\title{
Study on the Organic Integration of Physical Education and Online
}

\section{Education}

\author{
Shiqing $\mathrm{Le}^{1}$, Yuan Wen ${ }^{2}$ \\ ${ }^{1}$ Sports Department, Nanchang Institute of Science and Technology, Nanchang Jiangxi 330108, \\ China \\ ${ }^{2}$ Sports Department, Nanchang Institute of Science and Technology, Nanchang Jiangxi 330108, \\ China \\ 346591653@163.com
}

KEYWORDS: Physical Education, Online Education, Organic Integration

\begin{abstract}
With the continuous development of new curriculum reform, quality education has been widely accepted. Physical education is an important part of college quality education, to improve the overall quality of students has an important role. Development of network information technology makes the current trend is beginning to show and the integration of online education and physical education. Innovative forms of online education teaching physical education, physical education to some extent, improve the teaching methods of online education, the organic integration of the two complementary advantages, work together to promote higher education to create a broader space for development.
\end{abstract}

\section{Introduction}

The development of modern science and technology, making online education began to rise. Online education network using modern information technology can be a variety of organic teaching resources together to achieve the optimal allocation of teaching resources, but also for students to create a variety of learning styles, so that they can be exempted from the restrictions of time and space for students to establish the concept of lifelong learning has laid a good basis in reality [1]. For physical education, the educators need to focus on seeking the meeting point of online education through sport and education network organic integration, thereby enabling the form of teaching physical education and teaching model can get the corresponding innovation and development, so that college sports educational level has been significantly improved.

\section{The Characteristics of the Organic Integration of Online Education and Physical Education}

\section{A. Multimedia Assistance Sports Teaching.}

Physical education usually involves more physical activity, physical education curriculum teaching activity is a significant feature of. College of Physical Education in the past is generally through teacher demonstration and explanation, thereby enabling students to master the appropriate movement skills. After a motor skills tend to be divided into several teaching, teachers will these actions demonstrate segment, and then demonstrate the continuity of this teaching approach, while having a strong intuitive, but students are often unable to master. After the Physical Education and the organic integration of online education, a more obvious feature is a multimedia sports teaching 
can help [2]. Use of multimedia, teachers can be some of the more abstract simulation of physical education and specific knowledge, through virtual technology text, maps, paintings, sound organic together, thus facilitating the students' understanding and grasp. Teachers will be in the form of the corresponding motor skills courseware show in front of students, so that sports teaching more intuitive and dynamic, students can according to their own understanding to grasp the essentials of action in order to achieve sports knowledge internalization and sublimation.

\section{B. Create Conditions for the Development of Physical Education.}

In general, there will be great practical differences between students, mainly from the students' life background, knowledge structure, cognitive ability and other comprehensive decision. There are individual differences among students, will have a different understanding and views on the same issue. For the same action sports, and some students can grasp well, some students it will be a corresponding difficulty understanding the phenomenon. Among the conventional physical education teachers usually need to face dozens of students to carry out teaching, within the constraints of teaching time, teachers to students is difficult to implement targeted teaching guide, thus making the concept of individualized not implement [3]. After the Physical Education and the organic integration of online education, Internet-based foundation, the teachers will be able to use the Internet for sports teaching. Internet sports teaching in two ways, namely, interactive tutorials, and a program of individual instruction, teachers are usually the application of individual guidance to the Sports Teaching. This teaching method is based on the multimedia, the complete contents of Physical Education presented, the sports teaching becomes illustrations and vivid. Teachers in this manner can be kept informed of student learning, which according to students' learning characteristics to adjust teaching strategies to enable students in physical education process can give full play to their initiative, teachers and then use personalized guidance to achieve individualized.

\section{Achieve Communication and Sharing of Teaching Resources.}

College Sports education is gradually showing comprehensive features, among physical education includes the social sciences and natural sciences. In the continuous development of education in colleges and universities today, the sports professional knowledge system is also gradually expand and extend. Simply use conventional textbook teaching, has failed to meet the practical needs of the current athletic evolving [4]. The Physical Education and education network organic together, can provide more resources for the teaching of Physical Education. The current network can be a library, research institutes and teaching resources into some advanced school library, the library contains a wide variety of sports teaching resources, including a virtual library, electronic books, online education, and so on. The database application to sports in colleges and universities, so that the teacher's way of obtaining information has become more convenient, which will also help the students to keep abreast of current development of sports, so as to achieve the purpose of expanding students' horizons sports.

\section{Achieve the Organic Integration of Physical Education and Online Education}

\section{A. Market Vision of Network Physical Education.}

With the continuous development of network information technology, online education has been gradually promotion and application. The current scope of application of online education among university is gradually expanding, especially organic integration of physical education and online education, physical education so that the network has a broad market prospect. China, as the largest developing country, is currently facing increasingly fierce international competition. In order to 
effectively improve China's comprehensive competitiveness, we need to accelerate the development of modern education among modern open education and distance education, in order to cultivate a number of modern high-quality personnel, and thus provide a strong intellectual support for China's economic development [5]. Therefore, the government needs to pay attention to the network to carry out physical education, not only need to increase funding to improve the infrastructure of colleges and universities, but also support the development of physical education from the network policy. Universities need to focus on the development of network physical education, so that students in the exercise of his body at the same time, you can learn the appropriate sports knowledge to improve their overall quality, to realize their full development.

\section{B. Physical Education Network Technology Matures.}

Universities in order to achieve the organic integration of physical education and online education, we need to pay attention to the network of information technology as an important support, and constantly improve the infrastructure. For now, our network of Physical Education technology is mature, the software and hardware facilities in colleges are also being gradually improved. The current education system is among the network of universities, hardware Cisco, Compaq, etc. occupy an important position, the domestic Tsinghua Tongfang and Lenovo products, also occupies a part of the market. Among the software, Oracle8i has OLTP summary management, high-end data warehouse technology and superior resources management and other functions, and thus provides users with a powerful control system resources, distance education is currently being occupied large market share. In the courseware, and usually it will be applied to Sun workstations, Tsinghua Unisplendour and Microtex occupy a larger share of the market. Major manufacturers are being gradually expanding online education market, we began to explore the importance of physical education technology research network, which is an organic integration of physical education and online education has laid a good basis in reality.

\section{Achieve the Network Physical Education.}

The current development of online education for the future development of physical education pointed out the direction to meet the objectives and requirements of the current educational modernization. Universities in this reality so that physical education and the organic integration of online education can not only expand the range of applications of online education, but also the progressive realization of the sport innovative teaching methods and teaching methods. For our part, in order to improve their overall national strength, it is necessary to the development of modern education, which is our country's education strategy decision. In order to make a more robust and diverse Personnel Training in Chinese universities, it needs to be applied to the base of online education in colleges and universities, in order to broaden their horizons of knowledge, so that students can focus on the future, a good grasp now. The current development of network information technology makes the network physical education can be achieved, while the national government and the policies and measures and provides an important guarantee for the organic integration of physical education and online education. Achieve network physical education can effectively improve the overall quality of university students, so that students achieve comprehensive development.

\section{Conclusion}

All in all, the development of network information technology makes physical education and online education began organic together, so that the development of space education in colleges and universities has been expanded and extended. Educators need to change teaching concepts, can 
advance with the times, blaze new trails, and thus meet the real needs of today's society to talents, and gradually realize the popularization of higher education.

\section{REFERENCE:}

[1] King Song On Fusion Network Education and Physical Education [J] Anhui Sports Science, 2013,03: 96-98.

[2] Zhou Yanhua, Tang Yumei, who Zhiwei Network Times New Ideas on Reform of Physical Education in Colleges and Universities [J] movement, 2014,01: 73-74.

[3] Ding Xiangdong Reflections on Evaluation of Physical Education Professional Social Network Environment [J] news front, 2015,02: 133-134.

[4] Chen, Jia Jun on College Physical Education Thinking Network Teaching [J] PLA Institute of Physical Education, 2011,04: 82-85.

[5] Tang Yuan Jin, Tang Gui Reflections on Evaluation of Physical Education Professional Social Network Environment [J] Yulin Teachers College (Natural Science), 2013,05: 101-105. 